\title{
Experimental Investigation on the Influences of Different Horizontal Fire Locations on Smoke Temperature Stratification under Tunnel Ceiling
}

\author{
R. K. Haddad ${ }^{1}$, R. Zulkifli ${ }^{1}$, C. Maluk ${ }^{2}$ and Z. Harun ${ }^{1 \dagger}$ \\ ${ }^{1}$ Universiti Kebangsaan Malaysia, Bangi, 43600, Malaysia \\ ${ }^{2}$ The University of Queensland, Queensland, 4072, Australia \\ †Corresponding Author Email: zambri@ukm.edu.my
}

(Received August 19, 2019; accepted December 15, 2019)

\begin{abstract}
The increased probability of fire occurrence in urban tunnels has led researchers to investigate this issue extensively. Although fire can occur at any point in a tunnel, the effect of fire source position on temperature distribution has not received considerable attention in most of previous investigations. In this research, the influences of varying horizontal fire source locations on temperature diffusion in particular maximum smoke temperature stratification beneath the ceiling has been investigated. A set of scale-down experiments was performed in a model tunnel [ $3 \mathrm{~m}$ (length) $\times 0.6 \mathrm{~m}$ (width) $\times 0.96 \mathrm{~m}$ (height)]. $\mathrm{n}$-Heptane and gasoline were used as fuels in rectangular pools to generate a heat source. The analysis reveals that typical temperature curves have a similar trend when the fire source location changes. Furthermore, the temperature profile tip (maximum smoke temperature) is located between the burner and the origin of the tunnel. The modified model of maximum temperature, which considers the horizontal fire source location, is defined. The results here complement existing literature where the effects of variable fire position in a tunnel have not been considered.
\end{abstract}

Keywords: Horizontal fire source location; Maximum smoke temperature; Model tunnel.

\section{NOMENCLATURE}

$\mathrm{C}_{\mathrm{P}} \quad$ specific heat capacity

D fire source diameter

Fr The Froude number

$\mathrm{H}$ tunnel height

$\mathrm{H}_{\mathrm{d}} \quad$ height from the fire surface to the tunnel ceiling

$\mathrm{H}_{\mathrm{T}} \quad$ net heat of complete combustion

g gravitational force

$\mathrm{k} \quad$ radiative emission coefficient

L tunnel length

$\mathrm{L} \quad$ distance between the centerline of the gas burner and the tunnel sidewall

$\dot{m}_{f} \quad$ fuel mass loss rate

$\dot{m}_{\infty} \quad$ burning rate for an infinite diameter pool fire

$\mathrm{Pa}_{\mathrm{a}} \quad$ ambient pressure

Q heat release rate of the fire source
$\mathrm{Q}^{*} \quad$ dimensionless heat release rate

$\mathrm{Q}_{\mathrm{C}}$ convective heat release rate of the fire source

$\mathrm{R}$ radius of the fire source

$\mathrm{T}$ smoke temperature

$\mathrm{T}_{\mathrm{a}} \quad$ ambient temperature

$\mathrm{V}$ longitudinal ventilation velocity

W tunnel width

$\mathrm{x} \quad$ distance away from the origin

$\gamma, \varepsilon \quad$ experimental constants in Eq. 1

$\kappa \quad$ dimensionless correction coefficient in Eq. 20

$\rho_{\mathrm{a}} \quad$ ambient air density

$\Delta \mathrm{T}_{\max }$ maximum excess gas temperature beneath the ceiling

\section{INTRODUCTION}

In recent years, expressway networks have increased dramatically to cater increasing demands. Subsequently, the number of underground tunnels has increased, which results in shorter transport time,

increased public transport capacity, and reduced traffic congestion. Meanwhile, the risks of serious accidents and catastrophic fires increases with the traffic volume in tunnels. Two examples of these types of fire are the Mont Blanc tunnel fire, which killed 39 people in 1999, and the Korean Daegu 
Subway fire, which killed 192 people in 2013. Therefore, tunnel fires have attracted considerable attention from researchers. Tunnel constructions is set to grow exponentially in the world's most populous continent-Asia. Under China's 'Silk Road' ambitions, the Chinese government will undertake the majority of the financing of railways and highways across the continent, from Eastern China to Pakistan and Northern China to Indonesia. Although investments have been viewed with cautions because of the financial terms and the rights to operate and own the infrastructure (Harun et al. 2019a), many of these projects seem to finally commence. In Malaysia alone, the East Coast Rail Line, which will have a few long tunneling works because it has to cross the country's mountain range, will proceed after renegotiation of financial and right terms (Harun et al. 2019b).

When fire occurs in a tunnel, combustion products, hot smokes, and even the fire flame spread to the ceiling and diffuse in the left and right directions. As a result, the temperature of concrete increases and collapses. Usually, the concrete structure of tunnels filled with steel bars, which are directly exposed to hot flow, result in a decrease in steel strength and structural stability, which destroys the tunnel structure. Consequently, to protect tunnel surface structure, organize fire evacuation, and arrange fire detectors, exploring the maximum temperature of smoke under the ceiling of a ventilated tunnel is a challenge. In most of the past research, the maximum temperature of hot gases has been examined regardless of the fire source location. For example, Haddad et al. (2016) performed a numerical simulation to examine the influence of ventilation velocity on the hot gas temperature stratification in a one-way mass rail transit. The results indicate an inverse proportional relationship between inlet velocity and the backlayering length. The present study focuses on this phenomenon and constructs a model to determine the maximum temperature under various fire source locations. The structure of this paper is as follows. First, a review of the models for specifying the maximum smoke temperature is compared and analysed. Subsequently, the influences of different longitudinal fire source locations on the maximum smoke temperature and temperature stratification are discussed, and a new model regarding the fire source location for estimating the maximum smoke temperature in a longitudinal ventilated tunnel is derived.

\section{DISCUSSION ON ANALYZED MODELS AND EXPERIMENTS}

Many researchers have developed models for quantifying smoke characteristics under the ceiling in case of a tunnel fire (Yan et al. 2009; Li et al. 2011; Li et al. 2012a; Ji et al. 2011). Research related to smoke properties, which focused on experimental and theoretical research, was reviewed by Haddad et al. (2019). However, most studies have aimed at addressing situations in which the burner is located at the origin of the tunnel; a few studies have considered the contexts of different longitudinal fire source locations. In 1972, an equation describing the maximum smoke temperature was proposed by Alpert (1972). Alpert considered a special aspect ratio of tunnel cross section (the distance between the fire source and the vertical walls was 1.8 times longer than the tunnel height); this requirement could not be met in the case of a tunnel fire. Therefore, further studies have been conducted to investigate the maximum smoke temperature when the fire is relatively close to the sidewall.

A theoretical model describing the maximum temperature of fire-induced flow was established by Kurioka et al. (2003) through model scale experiments. In the study of Kurioka et al. (2003), the dimensionless equation of the maximum temperature was correlated with the dimensionless heat release rate (HRR) and the Froude number (Fr). The Froude number is the ratio of inertia forces to gravitational forces. The derived relation is expressed as follows:

$\frac{\Delta T_{\max }}{T_{a}}=\gamma\left(\frac{Q^{* 2 / 3}}{F r^{1 / 3}}\right)^{\varepsilon}$

where

$\gamma=1.77, \varepsilon=1.2$ for $\left(\frac{Q^{* 2 / 3}}{F r^{1 / 3}}\right)<1.35$

$\gamma=2.54, \varepsilon=0$ for $\left(\frac{Q^{* 2 / 3}}{F r^{1 / 3}}\right)>1.35$

where

$Q^{* 2 / 3}=\frac{Q}{\rho_{c} C_{p} T_{a} g^{1 / 2} H^{5 / 2}}$

and

$\mathrm{Fr}=\frac{\mathrm{V}^{2}}{\mathrm{gH}}$

In above equations, $\rho_{a}$ is the ambient air density, $C_{p}$ is the specific heat capacity of air, $Q$ is the fire total HRR (kW), $g$ is the gravitational acceleration, $H$ is the tunnel height, Ta is the ambient temperature, and $V$ is the longitudinal velocity. $\Delta T_{\max }$ is the maximum temperature excess over ambient, $\gamma$ and $\varepsilon$ are coefficients depending on $Q^{* 2 / 3} / \mathrm{Fr}^{1 / 3}$. This model cannot provide precise results when the ventilation velocity is considerably low because it will cause the Froude number to be approximately zero. Hu et al. (2005) justified the results derived from Kurioka et al. (2003)'s study via full-scale fire experiments. The recorded maximum temperatures were lower than the values calculated by Eq. 1 due to lower HRRs used. The maximum smoke temperature under the ceiling in a tunnel fire was investigated experimentally and numerically by $\mathrm{Hu}$ et al. (2006). The maximum temperatures calculated by fire dynamic simulator (FDS), which was based on a computational fluid dynamics model of fire-driven fluid flow, were compared with the estimated maximum temperature calculated by Kurioka's empirical model; the estimated results were slightly higher than the FDS predicted values. Hu et al. (2007) performed full-scale experimental tests and used the obtained results to validate the results explored by numerical simulation. They found that the temperatures predicted by FDS 4.0 were close to the measured data in the experimental results. (4.0 
refers to the version of the software). Li et al. (2011) divided the maximum temperature of smoke into two regions on the basis of dimensionless ventilation velocity. They proposed the following equation by performing experimental tests and theoretical analysis:

$\Delta T_{\max }\left\{\begin{array}{lll}\frac{Q}{V r^{1 / 3} H_{d}^{5 / 3}} & \text { for } & V^{\prime}>0.19 \\ \frac{17.5 Q}{H_{d}^{5 / 3}} & \text { for } & V^{\prime} \leq 0.19,\end{array}\right.$

where

$V^{\prime}=\frac{u}{u^{*}}$

and

$u^{*}=\left(\frac{Q_{c} g}{r \rho_{a} C_{p} T_{a}}\right)^{1 / 3}$,

where $u^{*}$ is the dimensionless longitudinal wind speed, $r$ is the burner radius, $Q_{c}$ is the convective HRR of the fire plume, and $H_{d}$ is the vertical height between the fire source (gas burner) and the tunnel ceiling. Li et al. (2012b) theoretically and numerically investigated the temperature stratification of fire-induced flow. They derived a correlation through theoretical analysis for various aspect ratios and fire intensities. The fire-induced temperature distribution below the ceiling in a longitudinal ventilated metro tunnel was studied in a small-scale tunnel by Zhao et al. (2018). In this investigation, the temperature distribution in experimental tests with various ventilation velocities and HRRs was analyzed at downstream and upstream sections. On the basis of the experimental data, a modified model for temperature decay at the upstream side of fire source was derived, which had a modified coefficient related to the fire size and the ventilation velocity. In addition to the aforementioned model, the maximum ceiling temperature was obtained and studied experimentally and numerically by Gao et al. (2018). The maximum smoke temperature beneath the ceiling was confirmed to be proportional to the terms of $\mathrm{Q}^{2 / 3} / \mathrm{H}_{\mathrm{d}}{ }^{5 / 3}$. Gao et al. (2018) proposed modified equations for maximum smoke temperature and longitudinal temperature decay beneath the tunnel ceiling. A comparison analysis performed between experimental results and numerical simulations indicated that the differences were less than $7.5 \%$.

Previous studies have been performed to investigate the maximum smoke temperature in the case where the fire source is located at the center of the tunnel. Consequently, the influence of burner location on the maximum temperature of fire-induced flow re-quires further investigation because fire can occur at any longitudinal location in tunnels. Along with the same previously described methodologies (Kurioka et al. 2003; Hu et al. 2007; Li et al. 2011), some researchers have attempted investigate the influences of fire source locations on smoke characteristics. Lai et al. (2010) experimentally investigated smoke detector activation in a scaled tunnel with varying burner locations and concluded that the burner location affects on the fire plume. Tsai et al. (2011) provided a set of data on the effect of longitudinal fire location on maximum smoke temperature. According to Tsai's study, longitudinal fire location did not influence the maximum temperature. The influence of various horizontal fire source locations on the maximum thermal smoke temperature was studied in a small-scale ventilated tunnel model in Ji et al. (2012); this study is the first to report changes in maximum smoke temperature by the variation of horizontal burner locations. Fan et al. (2015) demonstrated the relationship between the maximum smoke temperature and the longitudinal length under the ceiling given that the enhancement of tunnel safety was influenced by the influence of the maximum smoke temperature beneath the tunnel ceiling. They concluded that the maximum smoke temperature was not evidently affected by longitudinal fire location. Tang et al.(2017) analyzed the maximum thermal temperature and temperature decay via experimental tests with three horizontal fire source locations. They concluded that the location of the gas burner and its distance to the side walls affect the transverse maximum smoke temperature. The authors also established a mathematical model to estimate the maximum temperature, where a dimensional coefficient was determined to examine the influence of horizontal fire source location on the temperature pro-file. The correlations are expressed as:

$$
17.5\left(1.33-\frac{0.331}{W / 2} \frac{Q^{2 / 3}}{H_{d}^{5 / 3}} \quad \text { for } \quad V^{\prime} \leq 0.19\right.
$$

$\Delta T_{\max }^{\prime}$

$\left(1.37-\frac{0.371}{W / 2} \frac{Q^{d}}{V r^{1 / 3} H_{d}^{5 / 3}} \quad\right.$ for $\quad V^{\prime}>0.19$,

where $\Delta T^{\prime} \max$ is the maximum thermal smoke temperature beneath the ceiling in a tunnel with different horizontal gas burner (fire source) location, 1 is the distance between the center line of the fire source and the tunnel sidewall, and $\mathrm{W}$ is the tunnel width.

As previously discussed, studies have concentrated on maximum smoke temperature, whereas the context of various fire source locations has yet to be investigated. The existing models for quantifying this phenomenon (Kurioka et al. 2003; Li et al. 2011; Gao et al. 2018) are based on the model in which fire source is positioned at the center of the tunnel, deriving from the effects of HRR and ventilation velocity on the maximum temperature of hot gases. Fire source location is an important parameter for defining the natural resistance between the fire and the ventilation flow, particularly for the local velocity in the vicinity of the fire source changing at different fire source locations. To address this challenge, this study developed a model that demonstrates the influences of different longitudinal fire source locations on maximum smoke temperature under the tunnel ceiling. A series of experimental tests was performed, and on basis of the test results, the maximum smoke temperature equation presented by Li et al. (2011) was corrected 
by a dimensionless correction coefficient, which could represent the influences of different horizontal gas burner (fire source) locations. In addition to investigating the maximum gas temperature rise in tunnels with both open portals, it has been analyzed in a portal-sealed tunnel model (Yao et al. 2018). In this study, the maximum smoke temperature was estimated by an empirical model considering fire location and fire. The results show that the maximum temperature decreases when the fire source moves toward the sealed end. This study focused on limited scenarios, including gas fuel and small fires; therefore, further practical studies should be conducted.

\section{MATERIALS AND METHODS}

\subsection{Model Tunnel}

A series of experimental tests was carried out in a reduced-scale model tunnel (1:50). The dimensions of the model tunnel are $3 \mathrm{~m}$ (length) $\times 0.6 \mathrm{~m}$ (width) $\times 0.95 \mathrm{~m}$ (height) with a rectangular cross-sectional area. The ceiling, the floor, and three side-walls are constructed from fireproof boards; and half of one side-wall is made of tempered glass, which provides smoke movement observation during experiments. The origin of coordinates is $136 \mathrm{~cm}$ from the right side of the tunnel. The side view of the tunnel is shown in Fig. 1. The similarity between the scaled model and the full-scale tunnel is important in a physical model. Both gas flow conditions and material properties, which show geometric similarity, kinematic similarity, and dynamic similarity, influence on a complete similarity. However, the thermal inertia of the involved material, turbulence intensity and radiation are not explicitly scaled, and the uncertainty due to the scaling is difficult to estimate, the general nature of the buoyancy driven flows generated by a fire is not dependent on scale (McCaffrey and Quintiere 1976). Non-dimensional numbers such as the Froude number, the Reynolds number, and the Richardson number describe the smoke flow conditions in case of tunnel fire. Although, these numbers should be the same in the scaled model as in the full-scale tunnel, it is not possible in most cases. Therefore, the main goal is the preservation of the Froude number as the Froude number is the ratio between inertia and buoyancy forces and the Froude scaling model is used to build the physical model of the tunnel (Heskestad 1973; Quintiere 1989). Regards to the Reynolds number, considering the ventilation velocity ranges used in this study and the dimension of the tunnel, it retains a sufficiently high value to ensure turbulent flow inside the tunnel. Preservation of the Froude number can be represented as:

$F r=\frac{V_{m}^{2}}{g L_{m}}=\frac{V_{F}^{2}}{g L_{F}}$,

where $L$ is the length. Subscripts $m$ and $F$ denote the proposed model and the full-scale tunnel, respectively. The scaling relationships for key parameters velocity and HRR are as follows:

$$
\begin{aligned}
& V_{m}=V_{F} \sqrt{\frac{L_{m}}{L_{F}}} \\
& Q_{m}=Q_{F}\left(\frac{L_{m}}{L_{F}}\right)^{5 / 2} .
\end{aligned}
$$

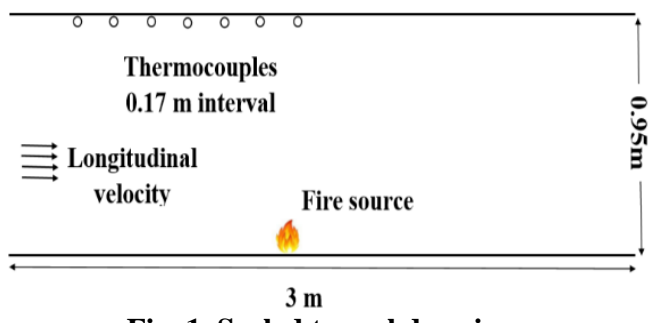

Fig. 1. Scaled tunnel drawing.

The longitudinal ventilation velocity is provided by an axial ventilation fan installed in the upstream end (the right side) of the tunnel. Ventilation velocity is controlled and calibrated by varying the voltage using a Toshiba frequency inverter VF-S11. The fan speed is calibrated with existing pitot tube and pressure transducer and having access at the wind tunnel located in the Beach and Water Resources Engineering Laboratory, National University of Malaysia (UKM) (Harun et al. 2016) made the calibration procedures easily accomplished. A section of $60-\mathrm{cm}$-long flow strengtheners including two metal mesh screens and a honeycomb mesh, is located between the fan and the test section for uniform longitudinal ventilation. The swirls created by the axial fan, were dampened by honeycomb mesh.

\subsection{Heat Release Rate}

Since gasoline and n-heptane have high carbon content, they need a lot of oxygen in case of complete combustion. In other words, because of dominant effect of oxygen supply compared to the cooling effect, the mass burning rate increases with the ventilation velocity for fuel controlled fires and approaches a constant value for well ventilated fires. Although, the restricting geometry of the tunnel causes less amount of oxygen, there is no block-ages between the fuel source and the fan which ex-plains the easy access of oxygen into the core of the fuel and well ventilated fire. The process of burning of a liquid fuel can be divided into three main stages; the initial stage, the transition stage, and the stable stage (Ji et al. 2015). Base on Ji's study, the mass burning rate of stable stage is used to calculate heat release rate. Although, without a de-tailed investigation of the induced reaction stages, we have to estimate the burning rate in order to assess the combustion time for a given initial amount of fuel. Here a simple method is proposed to estimate the maximum heat release rate in a ventilated tunnel fire, based on the burning rate. Pool fires of $2.73,5.26$, and $8.98 \mathrm{~kW}$ are generated by the ignition of n-heptane and gasoline in square vessels with dimensions of $0.0064,0.01$, and $0.0144 \mathrm{~m}^{2}$, respectively. These burners model fire is approximately equivalent to 48 $158 \mathrm{MW}$ in a real tunnel obtained based on an empirical relationship in Eq. 12 (Babrauskas and Peacock 1992): 
$Q=\dot{m}_{f} a H_{T}$

where $\dot{m}_{f}$ is the fuel mass loss rate, $H_{T}$ is the heat of combustion of the gaseous combustibles when oxidized completely under an ambient condition, and a is the burner area (Tewarson 1982). These fire sizes indicate the expected size of fires in private cars, public bus, and HGV. However, $\dot{m}_{f}$ and $Q$ are varied with time and ventilation velocity, based on the empirical relationship presented by Burgess et al.(1961), the burning rate with constant value is predicted in the function of pool diameter:

$\dot{m}_{f}=\dot{m}_{\infty}(1-\exp (-\mathrm{k} \Theta \mathrm{D}))$,

where $m_{\infty}$ is the burning rate for an infinite diameter pool fire, $\mathrm{k}$ is the radiative emission coefficient, $\Theta$ is the mean beam length corrector, and $D$ is the fire source diameter. The values used for n-Heptane are as follows:

$\dot{m}_{\infty}=0.101 \mathrm{~kg} / \mathrm{m}^{2} \mathrm{~s}$

$H_{T}=44.6 \mathrm{Mj} / \mathrm{kg}$.

$\mathrm{k} \Theta=1.1 \mathrm{~m}^{-1}$.

For gasoline:

$\dot{m}_{\infty}=0.055 \mathrm{~kg} / \mathrm{m}^{2} \mathrm{~s}$

$H_{T}=43.7 \mathrm{Mj} / \mathrm{kg}$.

$\mathrm{k} \Theta=2.1 \mathrm{~m}^{-1}$.

For example based on Eqs. 12 and 13 and the mentioned values $n$-heptane, the HRR for a $12 \mathrm{~cm}$ pool filled with $n$-heptane was calculated as follow:

$\dot{m}_{f}=\dot{m}_{\infty}(1-\exp (-\mathrm{k} \Theta \mathrm{D}))=$

$0.101 \times(1-\exp (-1.1 \times 0.14))=0.014 \frac{\mathrm{kg}}{\mathrm{s}}$,

and

$Q=\dot{m}_{f} a H_{T}=0.014 \times 0.0144 \times 44.6=8.98 \mathrm{~kW}$.

There is another method to estimate the heat release rate, the oxygen combustion method. Variations in oxygen concentration are typically between $21 \%$ and $18 \%$ during small scale testing and a high-precision oxygen analyzer is required. Consequently, calculating HRR by mass burning rate is more suitable. The influence of fire source location on the maximum smoke temperature is investigated considering the distance between the origin and new fire source location $(x)$. Five horizontal distances of $34,51,68,85$, and $102 \mathrm{~cm}$, are studied. The distance $x$ is shown in Fig. 2.

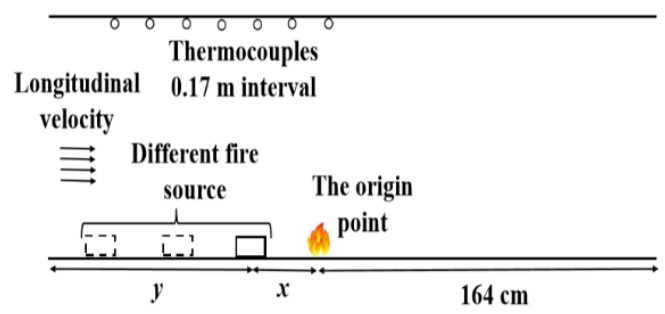

Fig. 2. Different fire source locations.

\subsection{Measurements}

An array of $8 \mathrm{~K}$-type thermocouples with intervals of $17 \mathrm{~cm}$ are placed in the central longitudinal section of the model tunnel to detect upstream back-layering flow and measure temperature distribution (Fig. 1). Calibration is performed prior to measurements by boiling water for the equipment. The time period during which the variation of temperature in the temperature profile is less than $2^{\circ} \mathrm{C}$ is taken as the quasi-steady condition. Two Arduino MEGA 2560 equipped with MAXX 6675 amplifier are used as a data acquisition system. Uncertainties of this measurement, which are estimated by calibration, instrument manual, and references, are shown in Table 1.

Table 1 Uncertainties of this experiment

\begin{tabular}{|c|c|}
\hline Instrument & Uncertainties \\
\hline K-type thermocouple & $2 \%$ \\
\hline Arduino MEGA 2560 & $0.25 \%$ \\
\hline Amplifier MAX6675K & $0.29 \%$ \\
\hline
\end{tabular}

As shown in Table 1, the recorded uncertainties in temperature are not expected to exceed $3 \%$.

\section{RESULTS AND DISCUSSION}

\subsection{Smoke Flow Behavior under the Effect of Longitudinal Fire Source Location}

Three types of boundary conditions are assumed in this research. Atmospheric boundary condition is applied at the right end of the tunnel, and as it is fully open, air flow is not restricted. At the left end, an uniformly distributed velocity boundary condition is produced. The velocity profile through the tunnel changes constantly and then will be fully developed within an infinite distance from the fan section. At the initial situation everywhere in the tunnel has $\mathrm{T}=$ $T_{a}$ and $P=P_{a}$. The tunnel walls are made of fireproof boards with the thickness of $25 \mathrm{~mm}$ and conductivity of $0.08-0.14 \mathrm{~W} / \mathrm{mK}$. It is assumed that there is noslip boundary condition, zero surface velocity, on the tunnel structural walls as well as no heat transfer through them. When a fire breaks down in the tunnel, hot gases current, which impinges on the tunnel ceiling, diffuses in both up-stream and downstream directions along the tunnel ceiling although only the downstream propagation is taken into account in this study. If the fire source is estimated as a point source, the schematic view of fire plume is shown in Fig. 3. With the assumption of constant heat release rate and axisymmetric plume, the flow field is subdivided into five zones (Kunsch (1998)) (Fig. 3): growing plume, turning region adjacent the ceiling, radial propagation, transition from radial diffusion to onedimensional, and one-dimensional flow. When a smoke flow travels along the tunnel, there would be a boundary layer contacting the tunnel ceiling. If friction between smoke plumes and the ceiling, air entrainment, and heat transfer to the ceiling are considered in one-dimensional diffusion zone under the ceiling, the following steady-state equations are presented (Kunsch (1998)):

- Mass: 
$\frac{d\left(\rho V h_{p}\right)}{d x}=\rho_{0} w_{e}$

where we is the entrainment velocity for point $\mathrm{e}$ in Fig. 3.

- Momentum:

$\frac{d\left(\rho h_{p} V^{2}\right)}{d x}=-\frac{d\left(1 / 2 g_{c}\left(\rho_{0}-\rho\right) h_{p}^{2}\right.}{d x}=-\rho_{0} w_{e} V-\tau$,

where the buoyancy of the hot gases is accounted by the factor $g_{c}$ and the shear stress $(\tau)$ is defined to taking account the friction between the plume and the ceiling.

- Bouyancy flux:

$\frac{d\left(\rho h_{p} u_{i}\right)}{d x}=\rho_{0} w_{e} i_{a}+\dot{q}$,

where $\mathrm{i}_{\mathrm{a}}$ is the ambient enthalpy and $\dot{q}$ is the heat flux due to heat transfer.

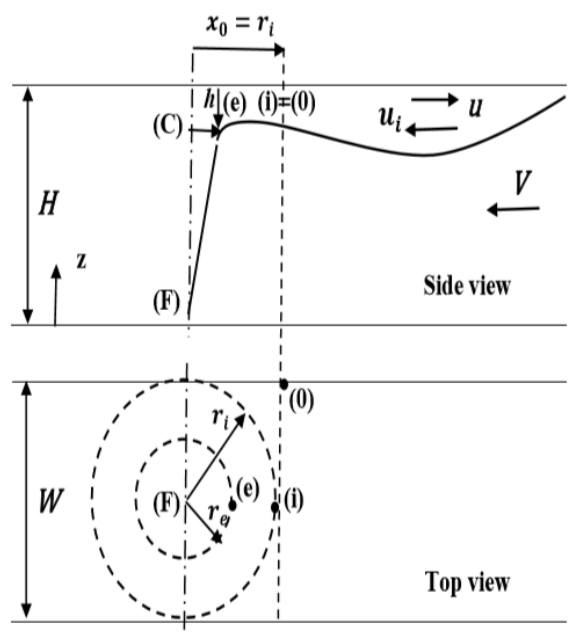

Fig. 3. Fire plume schematic view.

The control volume of frontal region of the fire-gas plume is shown in Fig. 4. The above equations are for the cases when the fire source is positioned at the origin. The fire makes an obstacle by its buoyancy force against the longitudinal velocity, which means the local velocity in the vicinity of the fire source is increasing. When the distance between the fire source and the fan reduces, the larger blockage and consequence acceleration in the local velocity is estimated. The buoyancy resistance of smoke flow becomes weaker which means the amount of smoke velocity in momentum equation decreases. Consequently, the air entrainment velocity, which is proportional to the velocity of the fire-gases relative to the air flow, declines. Therefore, the maximum smoke temperature will be different with that of a fire source at the tunnel longitudinal centre. It should be mentioned that if there was under ventilated conditions, the inflow of air is not influenced by the fire source location in the tunnel, which is against the above analysis. Figs. 5a) and b) show the smoke flow behavior when the ventilation velocity is smaller than the critical velocity and under the critical velocity, respectively, when the fire source is in the origin of the tunnel. Meanwhile, when the distance between the fire source and the fan is reduced, that is, the burner approaches the left side of the tunnel, some of the fire-induced smoke will easily spill from the honeycomb mesh (Fig. 5c)), which decreases the resistance of the buoyant smoke against the longitudinal ventilation. Thus the properties of backflow are different from the situation in which the distance between the fire and the end wall is sufficiently long. A portion of the smoke flows back to the fire location, which leads to the plume top being immersed in the smoke layer. In this section, the experimental fire is moved considerably closer to the fan section compared to the first objective. Under this condition, the maximum smoke temperature is investigated considering the fire source location.

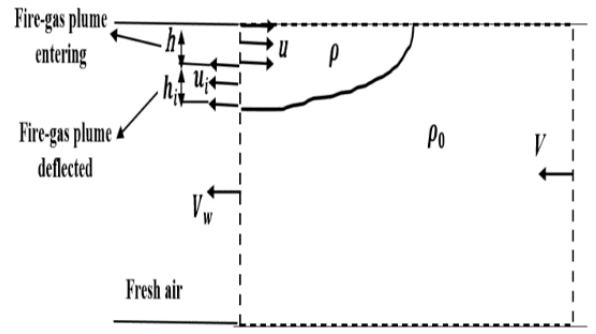

Fig. 4. Control volume of calculating the boundary condition at one-dimensional zone.

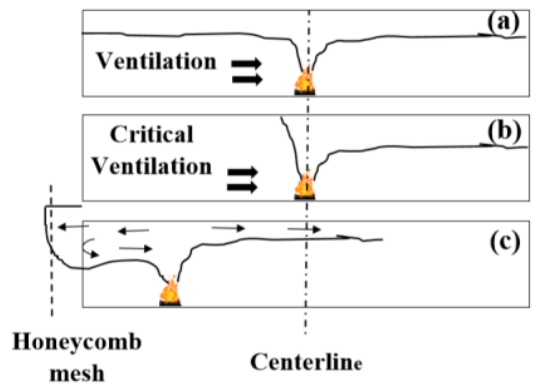

Fig. 5. Schematic view of smoke flow a) with the ventilation velocity smaller than the critical velocity, b) under the critical velocity, and c) when the distance between the fire source and the fan is reduced.

\subsection{Influence of Fire Source Location on Maximum Temperature}

Typical temperature profile measured by thermocouples is plotted in Figs. 6 and 7 as a function of time at various locations (each located $17 \mathrm{~cm}$ apart). The influences of fire source locations on temperature distribution are examined by considering experiments with the same HRR and ventilation velocity, although the fire source is located in various positions. For example, Fig. 6 shows the temperature profiles for $2.73 \mathrm{~kW}$ fire at $0.7 \mathrm{~m} / \mathrm{s}$ velocity in which the fire sources are positioned at $0,34,102 \mathrm{~cm}$ from the origin of the tunnel. Despite the difference in the fire source location, the curves are similar to one another in tendency: growing, steady, and decaying stages (Figs. 6 and 7). As shown in Fig. 6, it can be found that temperatures rise sharply from the ambient temperature to a relatively steady value at approximately $3000 \mathrm{~s}$, and the temperatures begin to decrease due to the decay of HRR at approximately 9000 s. The temperature profiles near the fire source 
increase considerably faster than those located far away from the fire source. For instance, the mode with $5.26 \mathrm{~kW}, \mathrm{x}=68 \mathrm{~cm}$, and $1.25 \mathrm{~m} / \mathrm{s}$, the temperature curve of thermocouples located at $51 \mathrm{~cm}$ and $68 \mathrm{~cm}$ from the origin increase faster than thermocouples located at $102 \mathrm{~cm}$ and $119 \mathrm{~cm}$ from the origin. The maximum smoke temperature is detected at a later time at positions further away from the fire, which is different for scenarios that the fire source is not at the origin. Li et al. (2011) found that the location of maximum smoke temperature is above the fire source when it is at the center of the tunnel. When the fire source moves toward the fan ( $x$ increases), the shape of fire plume changes. As it is clear from Fig. 8, the tilt angle between the tunnel floor and the axis of flame is smaller while the fire source is positioned at a distance closer to the fan. Therefore, the position of the maximum temperature will be shifted to the downstream to the fire source, between the fire source, and the center of the tunnel. This phenomenon is due to the flame deformation moving toward the fan. The flame bends toward the bottom of the tunnel as it approaches the fan, while simultaneously drawing toward the ceiling of the tunnel. Figure 8 shows samples of flame shape for different fire source locations. Figure 9 shows the temperature rise of the model-scale experiments with varying dimensionless longitudinal fire locations. $\Delta \mathrm{T}_{\max }^{\prime}$ is the maximum temperature of hot gases when the burner is in a location other than the center of the tunnel, and $x$ represents the distance between the fire source and the origin. At the
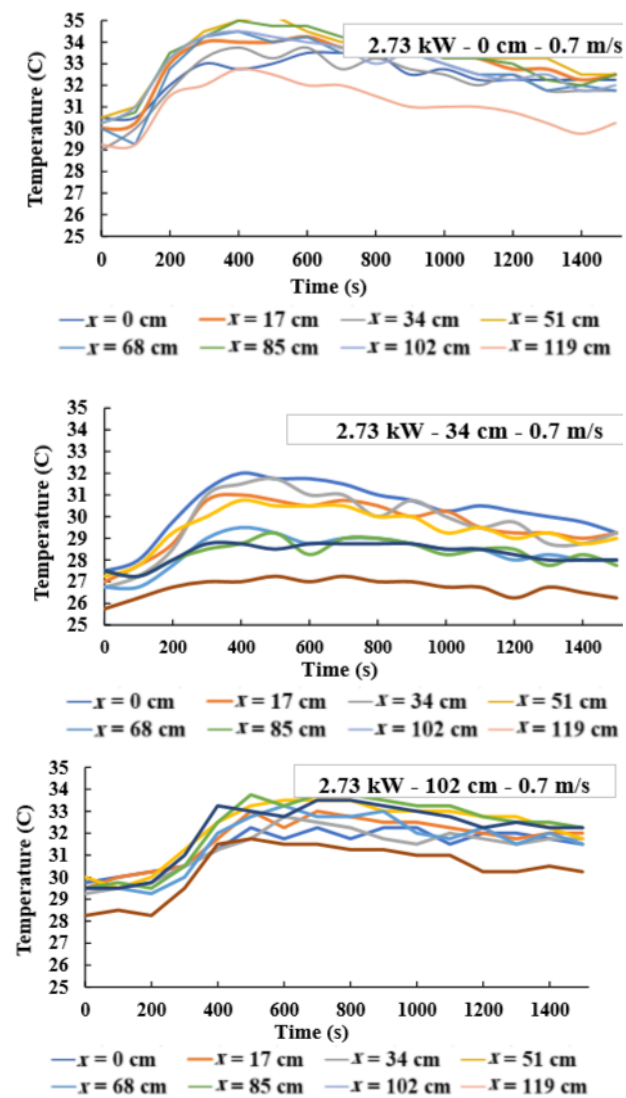

Fig. 6. Temperature profile of $2.73 \mathrm{~kW}$ fire at 0.7 $\mathrm{m} / \mathrm{s}$ for different fire source locations.

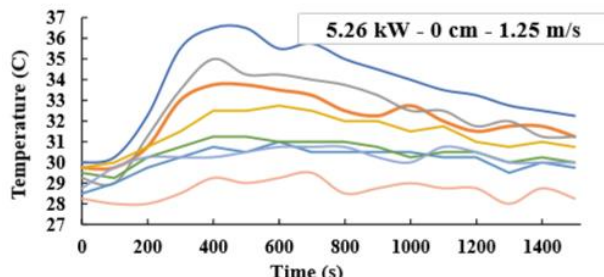

$-x=0 \mathrm{~cm} \quad-X=17 \mathrm{~cm}-X=34 \mathrm{~cm} \quad-X=51 \mathrm{~cm}$

$-X=68 \mathrm{~cm} \quad-X=85 \mathrm{~cm} \quad-X=102 \mathrm{~cm}-X=119 \mathrm{~cm}$

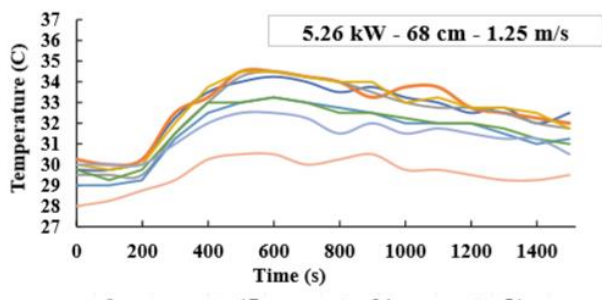

$-x=0 \mathrm{~cm} \quad-x=17 \mathrm{~cm} \quad-x=34 \mathrm{~cm} \quad-x=51 \mathrm{~cm}$ $-x=68 \mathrm{~cm} \quad-X=85 \mathrm{~cm} \quad-X=102 \mathrm{~cm}-X=119 \mathrm{~cm}$

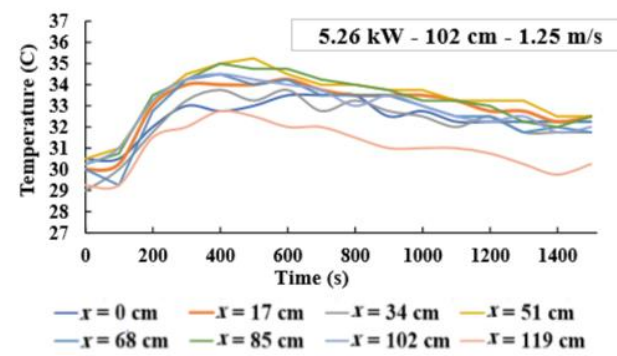

Fig. 7. Temperature profile of $5.26 \mathrm{~kW}$ fire at $1.25 \mathrm{~m} / \mathrm{s}$ for different fire source locations.
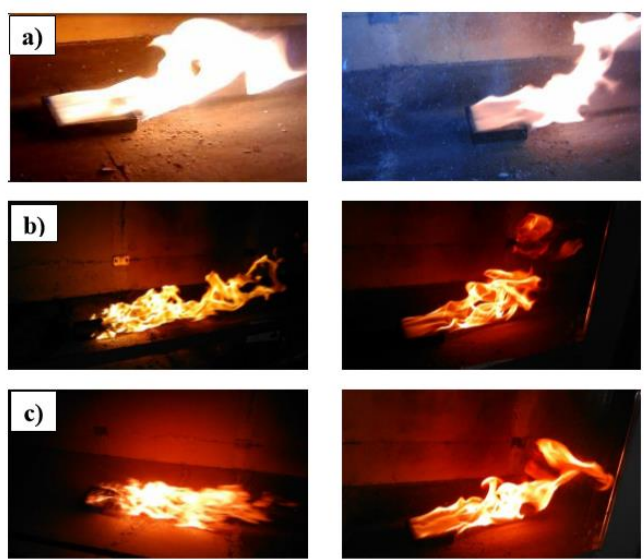

Fig. 8. Pictures of flame shape for two different scenarios: a) fire source at the origin, b) and c) fire source in a place other than the origin.

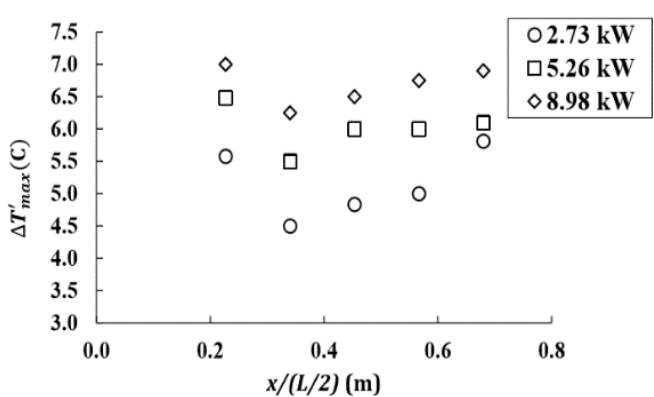

Fig. 9. Maximum temperature rise versus various dimensionless longitudinal fire locations. 
same position, with the increasing of the fire size, the temperature rise increases because more heat to the surrounding air is released by a larger pool fire and induces a smoke layer with higher temperature. As $x$ increases, $\Delta \mathrm{T}_{\max }^{\prime}$ initially decreases and then increases. The decrease in the first stage is due to the obstacle role of the fire source, which increases with a larger $\mathrm{x}$. This blockage effect accelerates the local velocity near the fire source, which in turn decreases the temperature of the buoyant flow. In addition, portion of smoke spills outside, which will induce a small fire. Although the maximum temperature rise increases when the dimensionless longitudinal distance is more than 0.340 given the back-flow of smoke, it enhances the turbulence of flow, which causes high smoke temperature. This factor overcomes the blockage effect. Li et al. (2011) found that the maximum temperature of smoke increases with the HRR and decreases with ventilation velocity. On the basis of small-scale experiments performed in this study, the equations pro-posed by $\mathrm{Li}$ et al. (2011) for the maximum excess gas temperature (Eq. 5) are amended considering the effect of horizontal fire source location on the maximum smoke temperature. Five horizontal locations are investigated. The experimental results are compared with the predictions by Li et al.(2011) in the first stage. As shown in Fig. 10, Li's model overestimates the maximum excess gas temperature beneath the ceiling when $\mathrm{V}^{\prime}>0.19$. The prediction of error is approximately $30 \%$. There-fore, a dimensionless correction coefficient is defined to examine the influences of various horizontal fire source locations on the maximum temperature profile. In other words, the maximum smoke temperature equation represented by $\mathrm{Li}$ is corrected as follows:

$$
\Delta T_{\max }^{\prime}\left\{\begin{array}{ccc}
\kappa \frac{Q}{V r^{1 / 3} H_{d}^{5 / 3}} & \text { for } & V^{\prime}>0.19 \\
17.5 \kappa \frac{Q^{d}}{H_{d}^{5 / 3}} & \text { for } & V^{\prime} \leq 0.19,
\end{array}\right.
$$

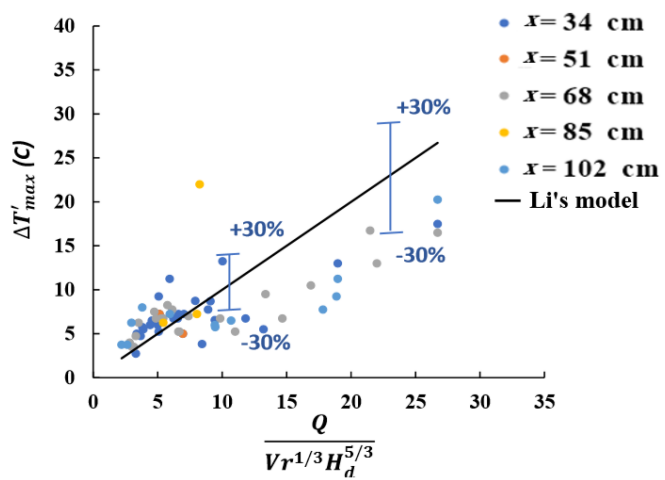

Fig. 10. Comparison between experimental maximum temperature rise results of this study and the proposed model by $\mathrm{Li}$ et al. for different fire source locations

where $\kappa$ is a dimensionless correction coefficient that can represent the influences of different horizontal gas burner (fire source) locations on the maximum thermal smoke temperature profile. A normalized parameter, $x /(L / 2)$, is defined to analyze the relationship between the correction coefficient and horizontal fire source location. Figure 11 shows the dimensionless modification coefficient against the normalized $x /(L / 2)$. The relationship can be expressed as follows:

$\kappa=1.1385+(-0.5211) x /(L / 2)$ for $V^{\prime}>0.19(20)$

A general equation considering the influence of horizontal fire source location is proposed by substituting Eq. 20 into Eq. 19.

$\left(1.1385+\frac{(-0.5211) x}{\frac{L}{2}}\right) \frac{Q}{V r^{\frac{1}{3}} H_{d}^{\frac{5}{3}}} \quad$ for $V^{\prime}>0.19$ (21)

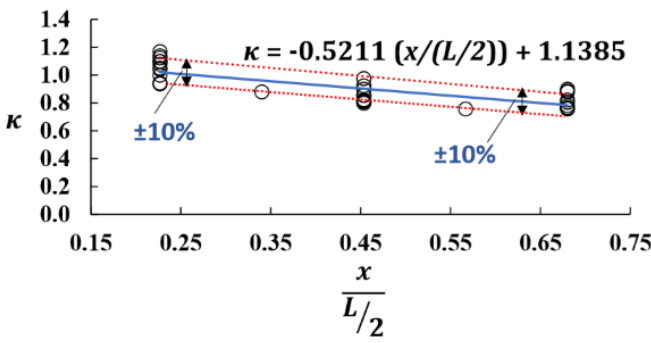

Fig. 11. Correlation of correction factor $\kappa$ with dimensionless distance $x /(L / 2)$.

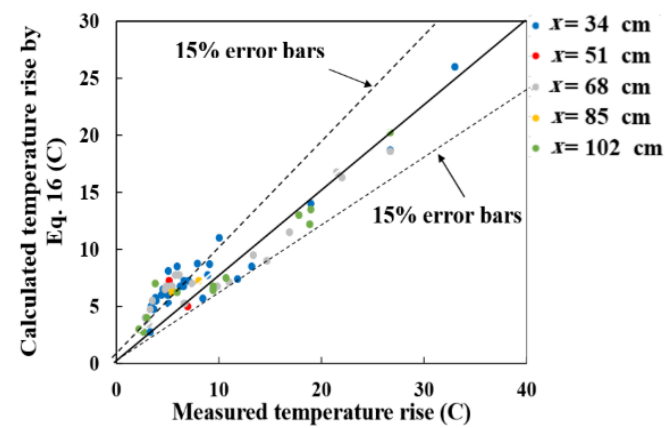

Fig. 12. Comparison between experimentally measured and calculated maximum thermal smoke temperature rises.

The comparison of the predictions by the revised Eq. 21 with the experimental measured values of the maximum thermal smoke temperature rise with different longitudinal gas burner locations is plotted in Fig. 12. From Fig. 12, Eq. 21 provides fairly good predictions of temperature rise of experimental tests (approximately 15\% difference). Densities are low at high temperatures, therefore performing tests with large fire size is necessary to complete this study. Given the short length of this model tunnel, Eq. 21 is evaluated with a longer tunnel; this condition causes a smaller $\frac{x}{L / 2}$, and a greater distance between the fire source and the fan, which results in a larger $\frac{x}{L / 2}$. Two assumptions, $\frac{x}{L / 2} \pm 10 \%$ and $\frac{x}{L / 2} \pm 30 \%$,are considered to determine the effect of the length of the tunnel, as well as longer distances between the fire source and the fan section on the proposed equation (Eq. 21). In the present experiments, $\frac{x}{L / 2}$ is between 0.227 and 0.56 , and $\mathrm{x}$ is between $0.34 \mathrm{~m}$ and $1.02 \mathrm{~m}$. 
For , $\frac{x}{L / 2} \pm 10 \%$, the maximum temperature rise has a difference of $2 \%$ with the values calculated by Eq. 21 . For $\pm 30 \%$ case, this difference is $7 \%$. The results obtained from the proposed equation show that this equation has little sensibility to changing the tunnel length and the variation in the distance between the fan and the fire source. However, the results presented here are limited to the method itself; in other words, the results and conclusions should be carefully treated and not be entirely extrapolated to real-scenarios cases. Figure 13 shows the calculated results of Eq. $21, \pm 10 \%$, and $\pm 30 \%$.
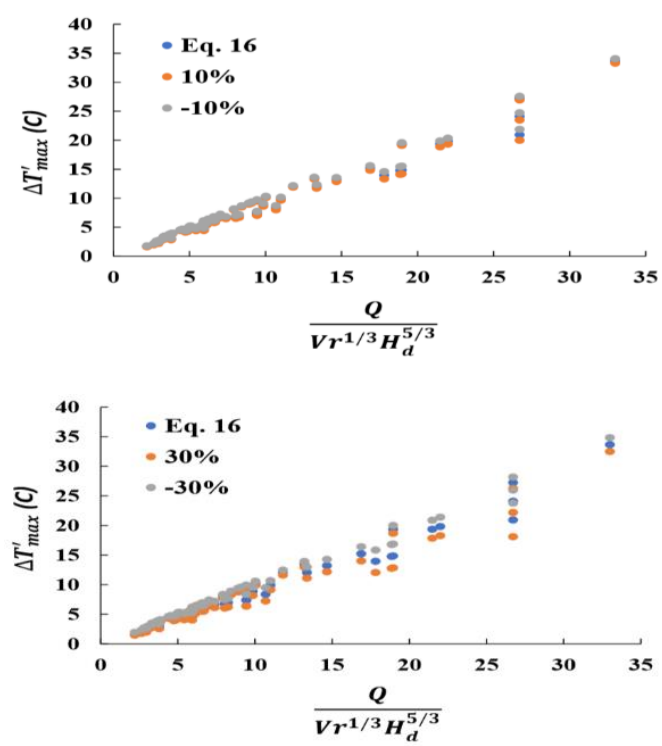

Fig. 13. Comparison between calculated maximum thermal smoke temperature rises with \pm 10 changes in $\frac{x}{L / 2}$ and \pm 30 changes in $\frac{x}{L / 2}$.

\section{CONCLUSIONS}

A small-scale experimental study is performed to investigate the effects of different horizontal fire source locations on smoke temperature beneath the ceiling during tunnel fires. Five burner locations are considered in this study. The experimental results are summarized as follows.

1. Typical temperature profile as a function of time in various fire source locations shows that the temperature curve has a similar trend under different fire source locations. The maximum temperature location is between the fire source and the center of the tunnel due to flame deformation and bend.

2. The test results show that the maximum temperature measured during the tests described herein correlates with the modeling work described by Li et al. (2011). Li's model overestimates the maximum thermal temperature beneath the ceiling when $\mathrm{V}^{\prime}>0.19$. Therefore, a dimensionless correction coefficient is defined to represent the influences of different fire source locations on the maximum thermal smoke temperature profile.
3. An empirical model is proposed considering the influences of fire source locations at 34, 51, 68, 85 , and $102 \mathrm{~cm}$. The model may be

used to derive the maximum temperature of smoke because it has achieved good agreement between the experimental results and the calculated maximum thermal smoke temperature rises using Eq. 21.

\section{ACKNOWLEDGMENTS}

We are grateful for the financial assistance provided by the FRGS/1/2016/TK03/UKM/03/1 grant of the Ministry of Education Malaysia (MOE) and GUP2018-102 provided by Universiti Kebangsaan Malaysia.

\section{REFERENCES}

Alpert, R. (1972). Calculation of response time of ceiling-mounted fire detectors. Fire Technology 8(3), 181-195.

Babrauskas, V. and R. D. Peacock (1992). Heat release rate: the single most important variable in fire hazard. Fire Safety Journal 18(3), 255272.

Burgess, D., A. Strasser and J. Grumer (1961). Diffusive burning of liquid fuels in open trays. Fire Research Abstract Review (United States) $3(3)$.

Fan, C., J. Ji and J. Sun (2015). Influence of longitudinal fire location on smoke characteristics under the tunnel ceiling. Fire and Materials 39(1), 72-84.

Gao, Y., G. Zhu, S. Gu, H. Tao and Y. Zhao (2018). Experimental and numerical studies on ceiling maximum smoke temperature and longitudinal decay in a horseshoe shaped tunnel fire. Case Studies in Thermal Engineering 12, 134-142.

Haddad, R. K., C. Maluk, E. Reda and Z. Harun (2019). Critical velocity and backlayering conditions in rail tunnel fires: State-of-the-art review. Journal of Combustion. 3510245.

Haddad, R. K., E. Reda, M. R. Rasani, C. M. Zedan and Z. Harun (2016). Fire simulation of a scaled mass rapid transit (MRT) tunnel. Journal of Mechanical Engineering S.I.7(1), 1-18.

Harun, Z., A. A. Abbas, B. Nugroho, L. Chan and S. Mat (2019a). Surface roughness effects studies in transportation industries. Jurnal Kejuruteraan S11(81-90).

Harun, Z., M. R. Rasani, W. A. W. Ghopa, A. A. Abbas, E. R. Lotfy, R. K. Haddad, T. A. Norizan, M. I. Ghazali and A. Abdulrazzaq (2019b). Turbulence research at Universiti Kebangsaan Malaysia: Experimental set ups, challenges and contributions. 5th International Conference on Recent Advances in Automotive Engineering.

Harun, Z., W. A. W. Ghopa, S. Abdullah, M. I. Ghazali, A. A. Abbas, M. R. Rasani, R. Zulkifli, 
R. K. Haddad et al. / JAFM, Vol. 13, No. 4, pp. 1289-1298, 2020.

W. R. Mahmood, M. R. Mansor, Z. Z. Abidin and W. H. Mohtar (2016). The development of a multi-purpose wind tunnel. Jurnal Teknologi 78(6-10).

Heskestad, C. (1973). Modeling of enclosure fires. In Symposium (International) on Combustion, Volume 14, pp. 1021-1030. Elsevier.

Hu, L., R. Huo, H. Wang and R. Yang (2007). Experimental and numerical studies on longitudinal smoke temperature distribution upstream and downstream from the fire in a road tunnel. Journal of fire sciences 25(1), 23-43.

Hu, L., R. Huo, W. Peng, W. Chow and R. Yang (2006). On the maximum smoke temperature under the ceiling in tunnel fires. Tunnelling and Underground Space Technology 21(6), 650655.

Hu, L., R. Huo, Y. Li, H. Wang and W. Chow (2005). Full-scale burning tests on studying smoke temperature and velocity along a corridor. Tunnelling and Underground Space Technology 20(3), 223-229.

Ji, J., C. Fan, W. Zhong, X. Shen and J. Sun (2012). Experimental investigation on influence of different transverse fire locations on maximum smoke temperature under the tunnel ceiling. International Journal of Heat and Mass Transfer 55(17-18), 4817-4826.

Ji, J., W. Zhong, K. Li, X. Shen, Y. Zhang and R. Huo (2011). A simplified calculation method on maximum smoke temperature under the ceiling in subway station fires. Tunnelling and Underground Space Technology 26(3), 490496.

Ji, J., Y. Fu, K. Li, J. Sun, C. Fan and W. Shi (2015). Experimental study on behavior of sidewall fires at varying height in a corridor-like structure. Proceedings of the Combustion Institute 35(3), 2639-2646.

Kunsch, J. (1998). Critical velocity and range of a fire-gas plume in a ventilated tunnel. Atmospheric Environment 33(1), 13-24.

Kurioka, H., Y. Oka, H. Satoh and O. Sugawa (2003). Fire properties in near field of square fire source with longitudinal ventilation in tunnels. Fire Safety Journal 38(4), 319-340.

Lai, C. M., K. J. Chen, C. J. Chen, C. T. Tzeng and T. H. Lin (2010). Influence of fire ignition locations on the actuation of smoke detectors and wet-type sprinklers in a furnished office.
Building and Environment 45(6), 1448-1457.

Li, J., S. Liu, Y. Li, C. Chen, X. Liu and C. Yin (2012a). Experimental study of smoke spread in titled urban traffic tunnels fires. Procedia Engineering 45, 690-694.

Li, L., X. Cheng, X. Wang and H. Zhang (2012b). Temperature distribution of fire-induced flow along tunnels under natural ventilation. Journal of Fire Sciences 30(2), 122-137.

Li, Y., B. Lei and H. Ingason (2011). The maximum temperature of buoyancy-driven smoke flow beneath the ceiling in tunnel fires. Fire Safety Journal 46(4), 204-210.

McCaffrey, B. J. and J. Quintiere (1976). Buoyancy driven countercurrent flows generated by a fire source. Hemisphere Publishing Company.

Quintiere, J. (1989). Scaling applications in fire research. Fire Safety Journal 15(1), 3-29.

Tang, F., L. Li, W. Chen, C. Tao and Z. Zhan (2017). Studies on ceiling maximum thermal smoke temperature and longitudinal decay in a tunnel fire with different transverse gas burner locations. Applied Thermal Engineering 110, 1674-1681.

Tewarson, A. (1982). Experimental evaluation of flammability parameters of polymeric materials. In Flame-Retardant Polymeric Materials, pp. 97-153. Springer.

Tsai, K. C., Y. P. Lee and S. K. Lee (2011). Critical ventilation velocity for tunnel fires occurring near tunnel exits. Fire Safety Journal 46(8), $556-557$.

Yan, T., S. Ming Heng, G. Yan Feng and H. Jia Peng (2009). Full-scale experimental study on smoke flow in natural ventilation road tunnel fires with shafts. Tunnelling and Underground Space Technology 24(6), 627-633.

Yao, Y., K. He, M. Peng, L. Shi, X. Cheng and H. Zhang (2018). Maximum gas temperature rise beneath the ceiling in a portals-sealed tunnel fire. Tunnelling and Under-ground Space Technology 80, 10-15.

Zhao, S., F. Liu, F. Wang and M. Weng (2018). Experimental studies on fire-induced temperature distribution below ceiling in a longitudinal ventilated metro tunnel. Tunnelling and Underground Space Technology 72, 281293. 